\title{
Contemporary ethnographic practice and the value of serendipity
}

\section{Contemporary ethnographic practice and the value of serendipity}

Serendipity, 'the art of making an unsought finding' (Van Andel 1994: 631), as juxtaposed to purposeful discovery by experiment or retrospective prophecy, is a much sought after ideal in scientific practice (Kirk and Miller 1986). The 18th-century English novelist Horace Walpole is believed to have coined the term, based on a Persian fairy tale, The Three Princes of Serendip, in which the main characters travel around making fantastic and unexpected discoveries (Bourcier and van Andel 2011: 41). Importantly, Walpole not only stressed the element of fortune or chance as part of the practice, but also that the discoverer needs to be 'sagacious' (knowledgeable) enough to link together apparently innocuous elements in order to come to a valuable conclusion or understanding (Merton and Barber 2004 [1958]). While serendipity is often misunderstood as referring only to the accidental nature and the delight and surprise of something unexpected, the masterful synthesis into insight by drawing novel connections is equally important (Fine and Deegan 1996). This requires sufficient background knowledge, an inquisitive mind, creative thinking and good timing.

Serendipity has a long history in science as having played a key role in many significant discoveries. As it involves both chance and sagacity, serendipity has been paraphrased as 'accidental wisdom' (Calhoun 2004). Decades ago, sociologist Robert Merton described the 'serendipity component' in qualitative research, a pattern that 'involves the unanticipated, anomalous and strategic datum which exerts pressure upon the investigator for a new direction of inquiry which extends theory' (Merton 1948: 506). This line of thinking inspired Barney Glaser and Anselm Strauss (1967) to develop serendipity as a scientific method in their 'grounded theory'. They widely diffused the idea that fruitful empirical research not only tests theoretically derived hypotheses, it also originates new ones. Their basic argument is that research questions should be defined narrowly enough so that the research remains focused and broadly enough to allow for flexibility and serendipity (based on a combination of both chance and intuitive reasoning).

In anthropology, serendipity, together with reflexivity and openness, is widely accepted as a key characteristic (and strength) of the ethnographic method. According to Frank Pieke, it even is 'the essence of fieldwork research' (2000: 138). The epistemological weight placed on serendipity in anthropology differs from the mere sagacious discovery Walpole described because it not only refers to an advantageous by-product of (participant) observation but also is deemed to shape the ethnographic process. Put differently, 'anthropologists are trained to observe what they are not prepared to see, 
[and] it is their main competence' (Olivier de Sardan 1995: 77). Indeed, the embodied capacity to 'conceptual distance', before starting reflexive interpretations, has long been the hallmark of the anthropological method. Marcel Mauss, for instance, argued that without being aware of one's own 'sociological perception' there can be no understanding: 'The young ethnographer embarking upon fieldwork must be aware of what he or she knows already, in order to bring to light what is not yet known' (2007: 8).

Serendipity has become a convenient notion to point out the very experience of suddenly coming to 'see' something that had previously been out of sight: the striking realisation that 'this is what it is about' ethnographic narratives refer to as the 'Geertzian moment' (cf. Geertz 1973). Over the past few decades, following the call for an epistemological de-construction of fieldwork as both a geographical, temporal and social unity of study and a narrative of cultural encounter (Clifford and Marcus 1986), numerous anthropologists have criticised the traditional approach to ethnographic fieldwork and writing. Relating this criticism to serendipity, two anthropologists recently published an edited volume entitled Serendipity in Anthropological Research: The Nomadic Turn (Hazan and Hertzog 2011). As the back cover explains, the book 'conceives of anthropological research as a lifelong nomadic journey of discovery in which the world yields an infinite number of unexplored issues and innumerable ways of studying them, each study producing its own questions and demanding its own methodologies'. The authors advocate for ethnographic fieldwork to change from a quest for alternative social and cultural cosmologies into a journey for exploring unexplored issues. Such propositions indicate that the focus of anthropological knowledge seems, indeed, to be shifting, raising questions about what the discipline is all about.

In this special section, we want to point out some of the changes in the framing of contemporary ethnographic research, with a shifting focus from place to time, from journeys to projects and situations, and from (expected) discoveries to methodological creativity. Rooted in the intellectual endeavour of investigating human unity through cultural diversity, anthropology has long focused on descriptions of 'Otherness'. Ethnographers who enter the discipline today, however, are more concerned with 'the challenge of the contemporary', to quote Dalsgaard (this issue). The challenge for them is to know how the people under study will manage to (re)invent sociocultural forms that suit the rapidly changing (global) context in which they live - and possibly find ethnographic vantage points to describe this.

\section{Fieldwork as a serendipitous journey, or not any longer?}

One of the prominent challenges for 'doing ethnography' nowadays is the uncertainty related to the definition of 'fieldwork', set to explore temporalities and their social refraction in people's lives - be it modern bureaucracies and regulations in detention centres, as in Le Courant's research, legal processes and the assertion of First Nations against modern states, as in Giabiconi's case, or craft and time in New Papua Guinea's politics, as in Dalsgaard's study (all in this issue). Field boundaries have often become looser than they were before and young scholars express uneasiness in adjusting to this 'situation' (Fogel and Rivoal 2009). All three articles in this special section thoroughly reflect on the idea of gaining access to 'the field' and the disquiet felt with any requested compromise. According to Dalsgaard, fieldwork 'emerges', for Giabiconi, one has to find the key to 'enter' the field, while it is more a matter of 'learning and practice' in 
Le Courant's experience. Clearly, fieldwork is multi-dimensional, requiring ethnographers to weave place, time and context together in ways that make any attempt at defining fieldwork in methodological terms difficult.

Serendipitous research requires 'time' - making time to observe, understand and ponder, and stretching time, if needed, to go back and forth between the traditionally separated periods of data gathering and analysis - a dimension of time that Dalsgaard brands as too linear to account for research loops. In the context of contemporary challenges, ethnographic intuition takes on temporal inflexions, much like the curiosity towards a peculiar or unfamiliar concatenation of events or circumstances. Serendipitous discoveries may be equated to 'epiphanies' (Garratt 1998) or, on the contrary, be seen as knowledgeably constructed affordances. Reflecting on the role of improvisation in jazz music, for example, Denis Laborde (2011: 153) suggests that serendipity is not only about meanings and situations, but may as well account for creating the illusion of spontaneity. In research, serendipity as such cannot be really 'planned', but the conditions facilitating the process can be manipulated.

There has always been a tendency in anthropology for the 'field' to shape the research design, rather than the other way around. Accidental sagacity has been intimately bound up with innovation in anthropology and beyond (Hazan and Hertzog 2011). It may seem ironic, but disasters often offer great potential for what Pertti and Gretel Pelto have called 'serendipity, disguised as catastrophe' (1978: 185). While conducting ethnographic fieldwork on cultural mobility in Yogyakarta, Indonesia, Noel Salazar (2010a) had to endure a volcanic eruption, a major earthquake and a minor tsunami. This series of unfortunate (and certainly unexpected) events heavily disrupted his original research plans but offered him instead a unique opportunity to study ethnographically the lived experience of disaster (which is rarely done, for the simple reason that such research cannot be planned on beforehand). Urged by colleagues at the University of Pennsylvania, his home institution at the time, he kept a widely read public weblog in which he shared first-hand ethnographic interpretations of what was happening in the immediate aftermath of the catastrophes (http://cli.gs/quake2006). The shared experience of dealing with loss and disorientation brought him much closer to his informants and shed new light on his original research questions.

Doctoral students in anthropology, who engage in fieldwork as an almost mandatory rite of passage, are faced with a dilemma. On the one hand, there is the expectation to conform to the almost mythical image of the lone fieldworker who stumbles upon people or places that capture the anthropological imagination. On the other hand, their fieldwork experience is structurally limited in time, resources and objectives, linked to an increasing number of rules set by funding agencies, government institutions, universities or other external agents (O’Dell and Willim 2012). Under such conditions, serendipity is not entirely impossible but less likely to occur (especially when reduced time for fieldwork is combined with reduced effort in appropriating sufficient 'background knowledge' in anthropological theory and methods).

Many scholars, including anthropologists, agree that the current socio-political and economic context in which science and knowledge production is embedded has induced undesired transformations in how academics in general have to work. Questions about how quickly science can produce new knowledge and innovation have become a widely acknowledged concern (Pels 2003). Much of the current critique revolves 
around the managerial and entrepreneurial performance culture that pervades the academic landscape today. The call of so-called 'slow science' advocates, however, is not necessarily one for more serendipity because that would imply stressing not only the need for more time (to increase the likelihood of chance events to occur) but also the need for better scientific training and excellence (to increase sagacity).

\section{The three princes of Serendip}

The critical task for the future is how to make what is generated by the exemplary works of established scholars through a rhetoric of serendipity, opportunity, and circumstantial, unexpected rupture encountered in what begins as the pursuit of traditional ethnography into an alternative paradigm of ethnographic method as legitimate as the traditional one. (Marcus 2002: 198)

Reflecting on the exchanges with his own graduate students, George Marcus notes that many are theoretically inspired by established scholars, but that these exemplars seldom offer a model to turn dissertations into innovative works. According to him, anthropological research is little served by the traditional rhetoric of discovery (which stresses chance but tends to omit sagaciousness), but instead must 'make method out of a rhetoric of circumstance' (Marcus 2002: 198). There will always be leaps of intuition, inferences that are not entirely supported, but anthropologists should, nonetheless, explain to their audiences, and especially to students in anthropology, how they came to their conclusions. The growing appeal of the notion of serendipity certainly highlights the lines along which contemporary scholars are endeavouring new ways of becoming anthropologists. Anthropology has already stepped outside the ivory tower of academia and being a young anthropologist entails both gaining ethnographic authority and defining one's own societal role as an anthropologist - a dilemma all authors explore convincingly in this special issue. We want to make three points here that need particular scrutiny in the light of appraising the future of the discipline.

\section{(1) The anthropologist as neo-nomad}

If we take a close look at what is advocated for by those propagating a 'nomadic turn' in anthropology (Hazan and Hertzog 2011), we see that the issue at stake is less a matter of fieldwork methods than a question of study objects and relevant research questions. The nomadic ethnographer is not set to decipher (solely) 'Otherness' anymore. Of course, this does not mean that cultures, cosmologies or alternate ways of inhabiting the world are not of interest anymore to anthropology. However, these are no longer the obvious and defined horizons of the discipline. What is at stake behind the urge for a renewed 'explorative disposition'? Such an ambitious project certainly calls for a disentanglement of the socio-cultural stances that have been the bedrock of anthropology, in order to embrace a serendipitous attitude, closer to the task Gilles Deleuze and Félix Guattari have set for philosophy, namely to create concepts (that are always novel) and to explain universals (Deleuze and Guattari 1994). Exploring unknown universals seems to be at the core (again) of the new anthropological project. Not surprisingly, such a project calls for new methodologies and a radical reappraisal of the ideal of Malinowskian-style fieldwork, designed to fit 
a drastically different conception of what concepts are to be held for: collective representations or a different Weltanschaunng (comprehensive worldview) to be investigated and compared as a way to settle universals.

\section{(2) The anthropologist as artist vs activist}

Is 'nomadic anthropology' challenging the anthropologist as an expert of and broker between 'cultures'? The traditional expertise of the profession has certainly dropped in value with processes of globalisation and the on-going commodification of the exotic - processes that have been scrupulously analysed by anthropologists (Salazar 2010b). What kind of knowledge are anthropologists producing when they are accounting for what is happening, here and now, at one locality or the other? How do they handle the 'qualitative distance' necessary to conduct research as opposed to producing expertise? Marilyn Strathern (2006) made an epistemological distinction between a managerial model of knowledge creation and a research model. She argued that both models differ in the temporal perspective they set out to address problems. Because experts are aiming at controlling uncertainties in the present time, they focus on ways to combine things in order to resolve or transcend past divisions. Research goes in the other direction: starting from an undivided past and exploring how it spreads from a core identity and generates multiple futures - research is the path toward creation (Strathern 2006). Is serendipity, then, a new word for creativity in the social sciences? Is it a panacea to avoid the pitfall of using ethnographies as mere contemporary contextualisations for events unfolding here and there? When is cultural expertise blurring the line between anthropologists and journalists or activists? What would the future of anthropology look like if we consider anthropologists along the lines of 'serendipitous creators', trying to carve out concepts as explanations for 'the chaos out there' (Deleuze and Guattari 1994)?

\section{(3) Multiple realities and methodologies: engaging the unity of the discipline}

The question at stake in this last point deals more with considerations concerning the inability of anthropologists to make themselves heard in the public arena (Eriksen 2006). If creativity is deemed the new anthropological horizon, the methodological unity of the anthropological project is challenged. Hence the need to address the methodological question thoroughly. This goes beyond exploring new ways of doing fieldwork, reflecting on new research methods or ways of understanding. Successful ethnographies used to be based on the ability to be part of the observed social world, developing relational skills and interest in playing different roles, to the point of 'atopy' - the ethnographical synthesis of multiple social positions (Naepels 1998). Lately, the aesthetical stance has gained power among ethnographers aimed at using their imagination as much as their training for distanced observation (Willis 2000: xi). Fieldwork has become a mise-en-scene, George Marcus says, nothing but a ready-made meta-method that only serves to enhance the solidarity of a profession that idealises itself throughout an idealised practice (Marcus 2009). James Faubion echoes the charge against the fieldworkas-a-meta-method, offering new ways to save the specificity of anthropology: it is time for anthropologists to shift from the idealisation of fieldwork and its serendipity (meaning here: having the time to carve out social relations, to soak in culture and learn to act accordingly) towards a common way of problematising 
the inquiry and conceptualising its objects with another kind of serendipity (Faubion 2009). Framed by these critics, serendipity has to be conceptualised anew as part of 'experimentation', used and manipulated as a research tool or process rather than as a concept merely indicating how observation unfolds. In other words, sagacity has to be reinstated as a principal component of serendipity.

\section{The serendipitous future of anthropology}

So is there a future for exploring exciting new horizons in anthropology? While recognising the increasing external pressures, good ethnographic work can and should never be completely orderly. It involves 'serendipity, creativity, being in the right place at the right or wrong time, much hard work, and old-fashioned luck' (Fetterman 2010: 2). Despite the changing circumstances, 'it is important to cultivate a certain willingness to seize unforeseen opportunities', as Daniel Miller suggested during the 2012 EASA Young Scholars Forum (see also this issue), a general sensibility towards ways of making anthropology out of realities that might otherwise remain mere distractions. And that also entails some readiness to 'depart from research plans and research designs that we carry into the field when we run into opportunities that simply should not be missed' (Hannerz 2006: 32). Serendipity, then, becomes 'an engine for moving anthropology forward, but at the same time it holds in store the promise and the prospect of derailing elsewhere towards other destinations' (Hazan and Hertzog 2011: 9).

The time is more than ripe to appraise some new horizons for anthropological inquiry and to launch an open-ended dialogue. The 2012 EASA Young Scholars Forum, held at the University of Paris Ouest Nanterre la Défense, which lay at the basis of this special issue, offered a space for reflection in which the value of serendipity was assessed in the context in which 'young' anthropologists are currently operating. Stefan Le Courant uses his work as a volunteer legal assistant and ethnographer among undocumented migrants in a detention centre in France to reflect on the 'boundaries' of fieldwork. He zooms in on the epistemological issues that this double engagement raises. To him, serendipity is closely related to the continuous oscillation between different researcher positionalities. Julie Giabiconi explores the tensions between dimensions of the personal self, the ethnographic self and the academic self in her fieldwork among a Dene First Nation in Canada - a classical anthropological study object. She argues that the profound uncertainty and disquiet infusing the everyday practice of the ethnographer can function as a heuristic tool to produce new (and relevant) anthropological knowledge. Finally, Steffen Dalsgaard proposes to conceptualise the 'field' as temporally constituted and to use a methodology of 'multi-temporal ethnography' to address the 'timeliness' of anthropological theory. Drawing on his fieldwork in Papua New Guinea, Dalsgaard shows how such an approach unpacks, serendipitously, the relationship between fieldworker and the field as it changes over time.

In conclusion, anthropologists, whether they are seasoned seniors or freshly minted graduates, should take time and rely on the discipline's accumulated wisdom to engage with research questions that they are genuinely interested in but that also have societal relevance. The three articles of this special issue masterfully illustrate how scientific inquiry in general and ethnographic research in particular is necessarily a slow but methodological and thoughtful process, an on-going quest for serendipity... 


\section{Isabelle Rivoal}

Laboratoire d'Ethnologie et de Sociologie Comparative (LESC)

CNRS/Université Paris Onest Nanterre La Défense

21, Allée de l'Université

92023 Nanterre cedex

France

isabelle.rivoal@mae.u-paris10.fr

Noel B. Salazar

Cultural Mobilities Research (CuMoRe)

University of Leuven

Parkstraat 45, bus 3615

BE-3000 Leuven

Belgium

noel.salazar@soc.kulewven.be

\section{References}

Bourcier, D. and P. van Andel 2011. Le long voyage d'une notion: la sérendipité, de la fiction à la science, in D. Bourcier and P. van Andel (eds.), La sérendipité, le hasard heureux, 41-51. Paris: Hermann.

Calhoun, C. 2004. 'Accidental wisdom: Robert Merton's serendipitous findings', Book Forum, Summer.

Clifford, J. and G. E. Marcus (eds.) 1986. Writing culture: the poetics and politics of ethnography. Berkeley, CA: University of California Press.

Deleuze, G. and F. Guattari 1994. What is philosophy? New York: Columbia University Press.

Eriksen, T. H. 2006. Engaging anthropology: the case for a public presence. Oxford: Berg.

Faubion, J. D. 2009. The ethics of fieldwork as an ethics of connectivity, or the good anthropologist (isn't what she used to be), in J. D. Faubion and G. E. Marcus (eds.), Fieldwork is not what it used to be: learning anthropology's method in a time of transition, 145-64. Ithaca, NY: Cornell University Press.

Fetterman, D. M. 2010. Ethnography: step-by-step. Los Angeles, CA: Sage.

Fine, G. A. and J. Deegan 1996. 'Three principles of Serendip: insight, chance, and discovery in qualitative research', Qualitative Studies in Education 9(4): 434-47.

Fogel, F. and I. Rivoal (eds.) 2009. La relation ethnographique, terrains et textes: mélanges offerts à Raymond Jamous. Theme issue, Ateliers du LESC 33.

Garratt, D. 1998. "Régime of truth" as a serendipitous event: an essay concerning the relationship between research data and the generation of ideas', British Educational Research Journal 24 (2): 217-35.

Geertz, C. 1973. The interpretation of cultures: selected essays. New York: Basic Books.

Glaser, B. G. and A. L. Strauss 1967. The discovery of grounded theory: strategies for qualitative research. Chicago, IL: Aldine.

Hannerz, U. 2006. Studying down, up, sideways, through, backwards, forwards, away and at home: reflections on the field worries of an expansive discipline, in S. Coleman and P. Collins (eds.), Locating the field: space, place and context in anthropology, 23-41. Oxford: Berg.

Hazan, H. and E. Hertzog (eds.) 2011. Serendipity in anthropological research: the nomadic turn. Farnham: Ashgate.

Kirk, J. and M. L. Miller 1986. Reliability and validity in qualitative research. Beverly Hills, CA: Sage.

Laborde, D. 2011. Improvisation, sérendipité, indétermination en musique, in D. Bourcier and P. van Andel (eds.), La sérendipité, le hasard heureux, 141-59. Paris: Hermann.

Marcus, G. E. 2002. 'Beyond Malinowski and after Writing Culture: on the future of cultural anthropology and the predicament of ethnography', The Australian Journal of Anthropology 13(2): 191-9.

Marcus, G. E. 2009. Notes toward an ethnographic memoir of supervising graduate research through anthropology's decades of transformation, in J. D. Faubion and G. E. Marcus (eds.), Fieldwork 
is not what it used to be: learning anthropology's method in a time of transition, 1-15. Ithaca, NY: Cornell University Press.

Mauss, M. 2007. Manual of ethnography. Oxford: Berghahn Books.

Merton, R. K. 1948. The bearing of empirical research upon the development of social theory, American Sociological Review 13(5): 505-15.

Merton, R. K. and E. G. Barber 2004 [1958]. The travels and adventures of serendipity: a study in bistorical semantics and the sociology of science. Princeton, NJ: Princeton University Press.

Naepels, M. 1998. 'Une étrange étrangeté: remarques sur la situation ethnographique', L'Homme 38(148): 185-99.

O’Dell, T. and R. Willim 2012. 'Irregular ethnographies: an introduction', Ethnologia Europaea 41(1): $5-14$.

Olivier de Sardan, J.-P. 1995. 'La politique du terrain: sur la production des données en anthropologie', Enquête 1: 71-109.

Pels, D. 2003. Unhastening science: autonomy and reflexivity in the social theory of knowledge. Liverpool: Liverpool University Press.

Pelto, P. J. and G. H. Pelto 1978. Anthropological research: the structure of inquiry. Cambridge: Cambridge University Press.

Pieke, F. 2000. Serendipity: reflections on fieldwork in China, in P. Dresch, W. James and D. J. Parkin (eds.), Anthropologists in a wider world: essays on field research, 129-50. New York: Berghahn Books.

Salazar, N. B. 2010a. Envisioning Eden: mobilizing imaginaries in tourism and beyond. Oxford: Berghahn.

Salazar, N. B. 2010b. Studying local-to-global tourism dynamics through glocal ethnography, in C. M. Hall (ed.), Fieldwork in tourism: methods, issues and reflections, 177-87. London: Routledge.

Strathern, M. 2006. 'A community of critics? Thoughts on new knowledge', The Journal of the Royal Anthropological Institute 12(1): 191-209.

Van Andel, P. 1994. 'Anatomy of the unsought finding. Serendipity: origin, history, domains, traditions, appearances, patterns and programmability', The British Journal for the Philosophy of Science 45(2): 631-48.

Willis, P. 2000. The ethnographic imagination. Oxford: Polity Press. 